\title{
Nuclear factor E2F mediates basic transcription and trans-activation by E1a of the human MYC promoter
}

\author{
Karin Thalmeier, ${ }^{1}$ Heidi Synovzik, ${ }^{1}$ Ronald Mertz, ${ }^{2}$ Ernst-Ludwig Winnacker, ${ }^{1,2}$ and Martin Lipp ${ }^{1,3}$ \\ ${ }^{1}$ Institut für Biochemie, Ludwig-Maximilians-Universität, D-8000 Munich 2, FRG; ${ }^{2}$ Laboratorium für Molekulare \\ Biologie-Genzentrum, Am Klopferspitz, D-8033 Martinsried, FRG
}

\begin{abstract}
Transcription from one of the two initiation sites, $P_{1}$ and $P_{2}$, of the dual human $M Y C$ promoter seems to be essential in all proliferating cells. To identify proteins and target structures for MYC regulation, a DNA region was analyzed that is critical for $P_{2}$ promoter activity. Here, we show that a nuclear factor binds to a DNA element within $P_{2}$, which is conserved perfectly between mouse and man and displays a striking homology to the E1a-inducible E2 promoter of adenovirus type 5 (Ad5). We demonstrate that the same transcription factor, defined recently as E2F, which plays an essential role in the activation of adenovirus early promoters and enhancers, also interacts as a dominant nuclear factor with the MYC promoter. The presence of an intact E2F binding site is required for basic expression and for trans-activation of the $P_{2}$ promoter by E1a proteins. The human MYC promoter is the first cellular target described for E2F. The results suggest that expression of MYC might be regulated via modulation of E2F by cellular 'E1a-like' factors.
\end{abstract}

[Key Words: Transcription activation; gene regulation; protein-DNA interaction; $M Y C$; E1a; E2F]

Received November 25, 1988; revised version accepted February 14, 1989.

Although the knowledge of transcriptional control in eukaryotic cells has advanced during recent years by the identification of elementary DNA sequence and nuclear factors interacting with these elements, the individual mechanisms leading to tissue-specific regulation during differentiation or to a characteristic deregulation during malignant transformation of certain genes are understood poorly. Recent studies suggest that multiple factors must cooperate and interact for enhancer- and tissue-specific transcriptional regulation and that different factors may recognize the same consensus sequence (for review, see Jones et al. 1988). The detection of a single yeast protein that has the ability of binding to two distinct DNA sequences has highlighted the puzzling complexity of transcriptional control (Pfeifer et al. 1987).

Viral systems have been analyzed extensively because their control elements are organized tightly. Recently, interest has focused also on the regulation of cellular oncogenes, some of which are deregulated consistently and expressed highly in certain types of tumors. Among the examples best analyzed are human and mouse $M Y C$ proto-oncogenes. They are activated by characteristic chromosomal translocations in Burkitt's lymphomas and mouse plasmacytomas, respectively (Klein and

${ }^{3}$ Corresponding author.
Klein 1985). Several studies have attempted to elucidate the regulation of the $M Y C$ gene by $5^{\prime}$ deletions, in vivo competition, and nuclear run-on transcription elements. The results suggest that multiple negative and positive regulatory elements, including transcriptional arrest within the first noncoding exon, are responsible for the steady-state level of MYC RNAs (Bentley and Groudine 1986; Chung et al. 1986; Eick and Bornkamm 1985; Yang et al. 1986; Hay et al. 1987; Lipp et al. 1987; for review, see Piechaczyk et al. 1987). Nevertheless, it is far from being understood which cellular transcription factors mediate repression or activation from the two $M Y C$ promoters $\left(\mathrm{P}_{1}\right.$ and $\left.\mathrm{P}_{2}\right)$ and how expression is modulated during differentiation, immortalization, and malignant transformation. In this study, we describe a cellular transcription factor binding efficiently to an element within the second promoter $\left(\mathrm{P}_{2}\right)$, which possesses binding specificities nondistinguishable from a nuclear protein, recently defined as E2F (Kovesdi et al. 1987). This factor plays a fundamental role in the activation of early promoters and enhancers of adenoviruses by interacting with the virus-encoded early Ela proteins. We demonstrate that binding of this factor to the second MYC promoter increases during adenovirus infection and is essential for its trans-activation by Ela. Furthermore, our results suggest that the activity of $P_{2}$ can be modulated by other cellular 'Ela-like' proteins (Imperiale et al. 1984) via the E2F transcription factor. 


\section{Results}

Cell-type-specific binding pattern of nuclear extracts to a MYC promoter fragment

The two promoters of the human MYC gene $\left(\mathrm{P}_{1}\right.$ and $\left.\mathrm{P}_{2}\right)$ are used differentially in certain cell types. $P_{2}$ dominates $P_{1}$ in most cell lines or tissues analyzed so far. However, in Burkitt's lymphomas, MYC becomes activated by consistent chromosomal translocations, and $\mathrm{P}_{1}$ is used preferentially. We have shown recently by $\mathrm{Sl}_{1}$ analysis that transcription initiates efficiently from $\mathrm{P}_{2}$ in 293 cells, a cell line constitutively expressing the Ela proteins of adenovirus type 5 (Ad5) (Lipp et al. 1989). Because these differences might reflect the presence or absence of distinct transcription factors, nuclear extracts of 293 cells and of the Burkitt lymphoma line BL64 were prepared and tested in gel retardation experiments with a 188-bp DNA fragment from the MYC promoter, denoted $\mathrm{f}-\mathrm{mycP}_{2}$, encompassing position -141 to +47 with respect to the transcriptional start site of $P_{2}$. As shown in Figure 1, crude nuclear extract of 293 cells gave rise to two specific DNA-protein complexes (A and B), whereas the extract of BL64 cells revealed only one complex band $(\mathrm{C})$ with an intermediate mobility compared to bands $\mathrm{A}$ and $\mathrm{B}$. The specificity of the DNA-protein complexes A, B, and C was demonstrated by competition analysis with a 50 -fold excess of unlabeled homologous promoter fragment (data not shown). However, the weak double band $\mathrm{E}$ (Fig. 1) did not disappear even with a 200 -fold excess of $\mathrm{f}-\mathrm{mycP}_{2}$, and therefore was considered provisionally as 'unspecific.'

To define more precisely the binding site of nuclear proteins within the 188-bp MYC promoter fragment, we took advantage of synthetic oligonucleotides to compete for particular sequences. Oligonucleotide myc-9/10 (Fig. 2; origin, see Fig. 1, bottom/ was chosen, because its sequence is highly conserved between human and mouse MYC promoters. Of $38 \mathrm{bp}$ of myc-9/10, $34 \mathrm{bp}$ are identical to the mouse sequence. As shown in Figure 1, bands $\mathrm{A}, \mathrm{B}$, and $\mathrm{C}$ disappeared completely when a 60 fold molar excess of unlabeled double-stranded oligonucleotide myc-9/10 was added. The pattern of complex bands did not alter in the presence of unrelated oligonucleotides Al/B1, EW-1/2, K-1/2 (Fig. 2). These results demonstrate that crude nuclear extracts from 293 cells and from Burkitt lymphoma cells form different DNAprotein complexes by recognizing a short $M Y C$ promoter sequence of $38 \mathrm{bp}$ represented by the oligonucleotide

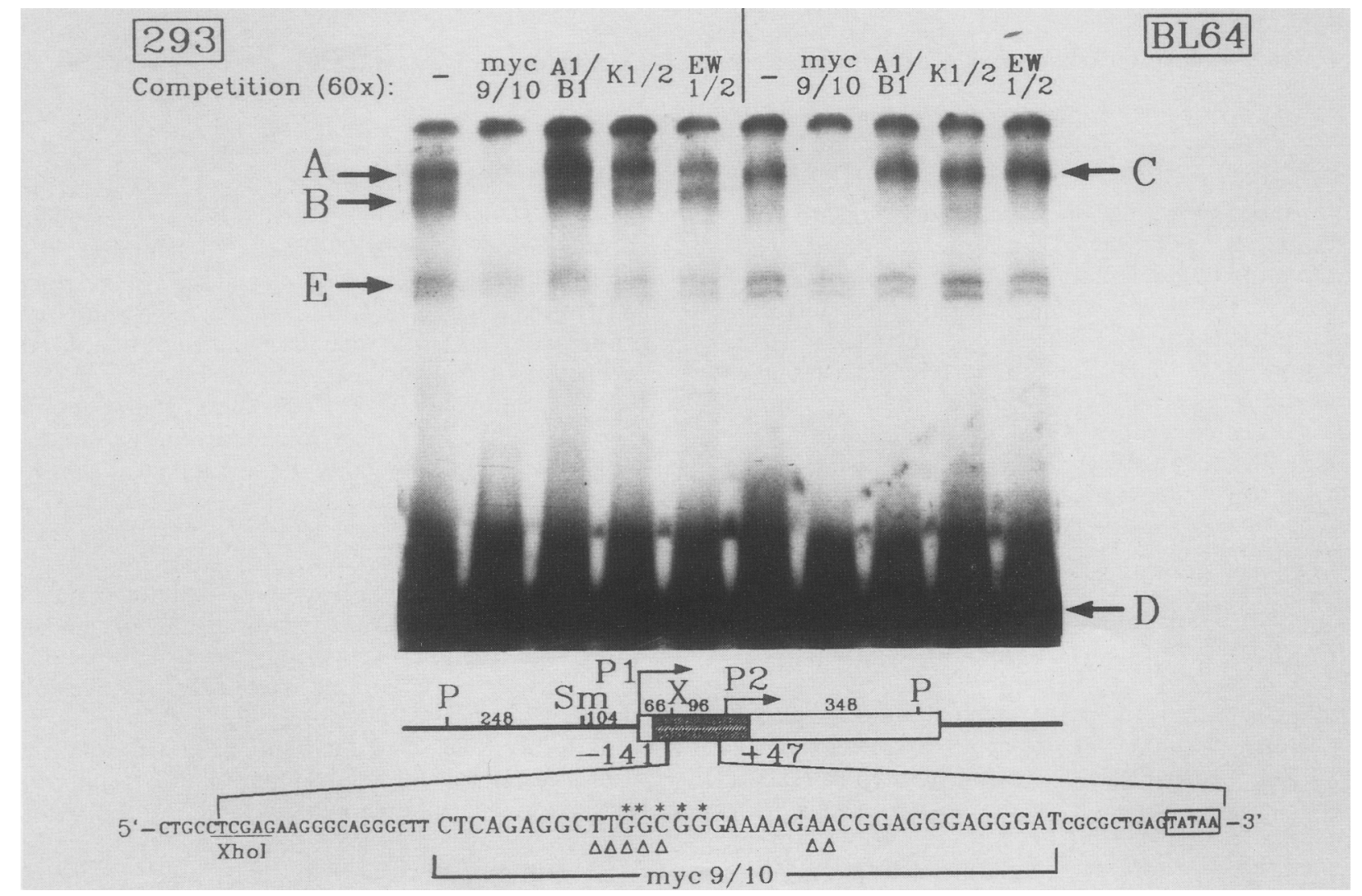

Figure 1. Gel retardation assay of the fragment $\mathrm{f}-\mathrm{mycP}_{2}$ with crude extracts of 293 and BL64 cells. In the presence of $2 \mu \mathrm{g}$ poly[d(AT)], 16 fmole of $5^{\prime}$ end-labeled f-mycP $\left.\right|_{2} \mid-141$ to +47 ) were incubated with $6 \mu \mathrm{g}$ of 293 extract (lanes 1-5) or BL64 extract (lanes $6-10$ ). Competition experiments were done by adding a 60 -fold molar excess of unlabeled double-stranded oligonucleotides (for sequence, see Fig. 2), as indicated above each lane. (A-E) DNA-protein complex bands; (D) the unbound fragment. (Bottom) The location of oligonucleotide myc-9/10 within fragment $\left.\mathrm{f}-\mathrm{mycP}_{2} .{ }^{*}\right)$ Homology to the core consensus sequence of transcription factor Spl; $(\triangle)$ homology to the consensus sequence of nuclear factor NFI. 


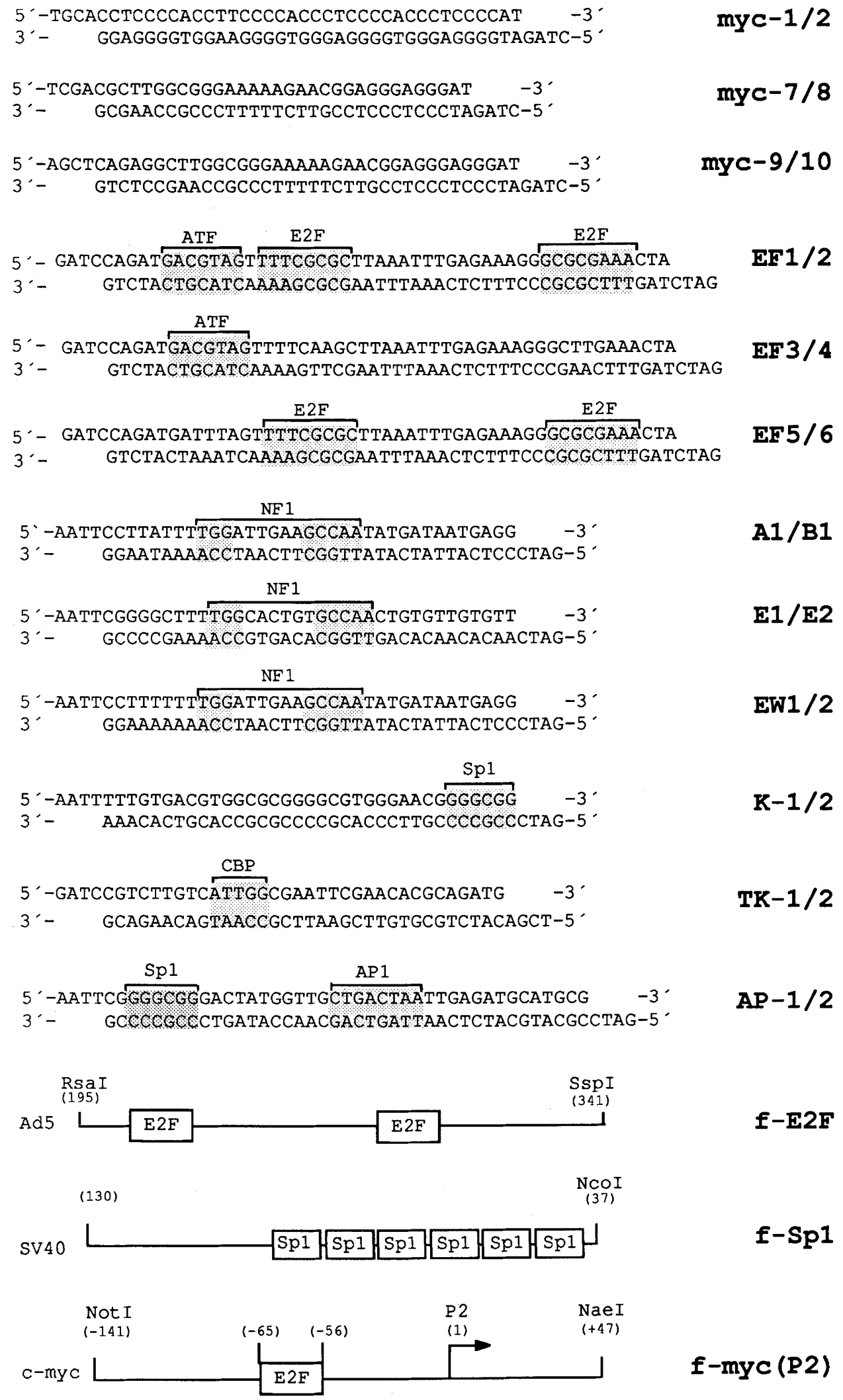

Figure 2. Synthetic oligonucleotides and DNA fragments used in gel retardation and competition experiments. Known binding sites for nuclear factors are indicated. 
myc-9/10 (identical results were obtained with the Burkitt lymphoma cell line JI).

\section{Interference of nuclear factors with a conserved DNA sequence of the second MYC promoter}

In an attempt to discriminate more accurately between the DNA sequences required for formation of the three complex bands A, B, and C, methylation interference analyses were performed. The partially methylated, endlabeled fragment $\mathrm{f}-\mathrm{mycP}_{2}$ was incubated with crude extracts of 293 and BL64 cells and analyzed by gel retardation assay. Bands corresponding to complexes A, B, C, and D (Fig. 1) were isolated from the gel. The DNA was purified, treated with piperidine, and analyzed on a sequencing gel (Fig. 3). In all DNA fragments retained by the three complexes, the identical five $G$ residues interfered with protein binding after methylation. This indicates that the sequence GGCGGG, which is totally conserved in the same position in the mouse c-myc promoter, is essential to form complexes A, B, and C.

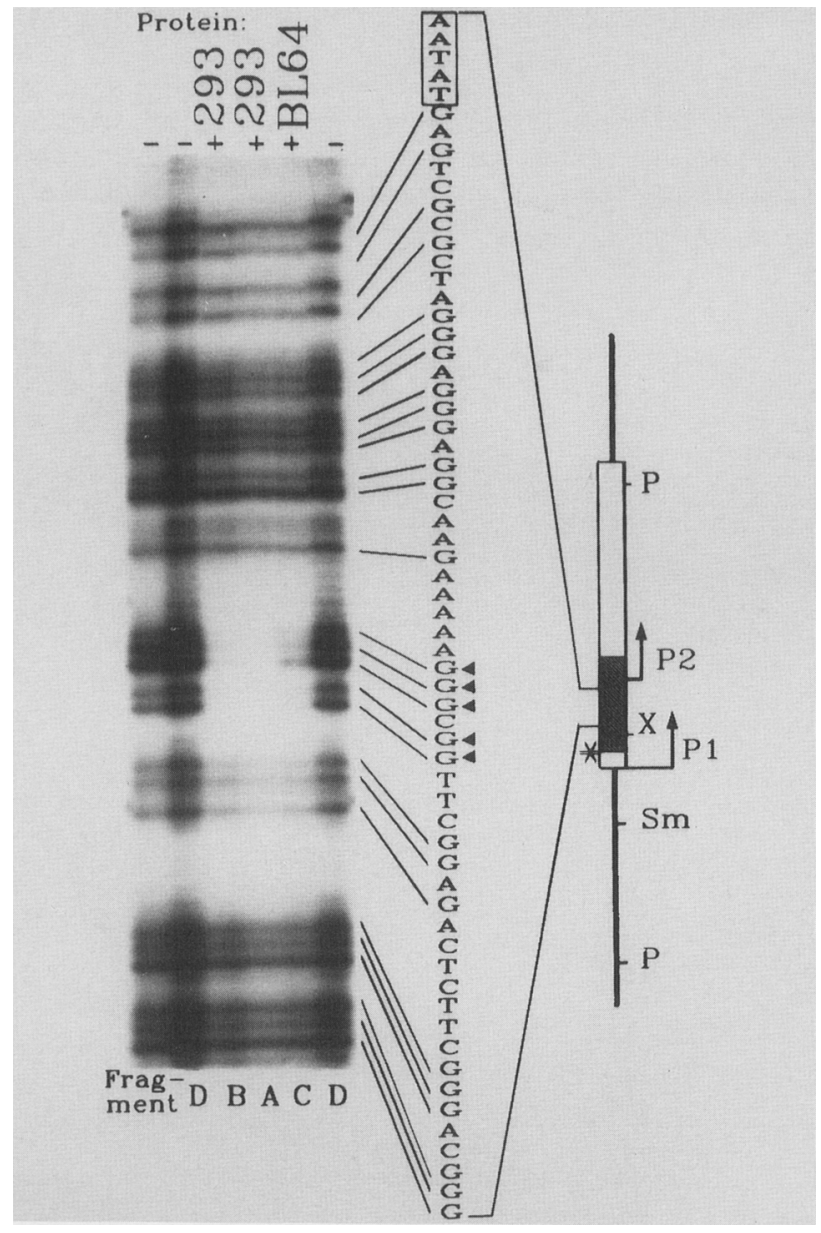

Figure 3. Footprint analysis of fragment $\mathrm{f}-\mathrm{mycP}_{2}$ by methylation interference. (Lanes $A-D$ ) DNA-protein complex $(+)$ or free fragment $(-)$ bands indicated in Fig. 1. (A) $G$ residues interfered with protein binding after methylation. For experimental details, see Methods.
Analogy in binding specificities of the MYC promoter fragment and an enhancer region of the adenovirus E1a gene

With the intention to purify $M Y C$-specific transcription factors, crude nuclear extracts prepared from HeLa cells were tested with fragment $\mathrm{f}-\mathrm{mycP} \mathrm{P}_{2}$ in gel retardation assays. This resulted in the same, but considerably reduced, binding pattern as obtained with extracts from 293 cells. Nuclear cell extracts from HeLa cells then were purified partially by conventional chromatography steps (see Methods), using gel retardation assays to identify fractions with DNA-binding capacities. One fraction of a Mono-Q column yielded a binding pattern identical to that of the crude extract and with the same specificities in competition experiments with control oligonucleotides (Fig. 4A). It was not possible to separate band A from band $B$ into discrete column fractions.

Keeping in mind that the $M Y C$ promoter can be transactivated efficiently by Ela proteins, we compared the DNA sequences of fragment $\mathrm{f}-\mathrm{mycP}_{2}$ with sequences from adenovirus early promoters known to be trans-activated by Ela. We found a striking homology to a region of the E2 promoter of Ad5 that is essential for trans-activation and is protected in footprint analysis (Kovesdi et al. 1986). Therefore, we proposed that a transcription factor with a similar recognition sequence should bind also to the MYC promoter. This hypothesis was proved by gel retardation competition experiments using the left-hand terminal HindIII fragment of Ad5 (f-Ad5H3-G) carrying two binding sites for a transcription factor that also binds to the Ela enhancer region included in the HindIII fragment, as well as to an upstream element of the E2 promoter. Recently, this factor has been defined as E2F (Kovesdi et al. 1987). As shown in Figure 4B, f-Ad5H3-G competed to a similar extent as the oligonucleotide myc-9/10 for nuclear factors forming bands $\mathrm{A}$ and B. Because the terminal fragment of Ad5 carries recognition sites for multiple nuclear factors (Jones et al. 1988), the specificity of competition was demonstrated by destroying the proposed consensus binding site for E2F (TTTCGCGC) with the restriction enzyme FnuDII (Fig. 4D). f-Ad5H3-G digestd with FnuDII did not compete for complex A and B (Fig. 4A), but the same fragment cut with HpaII (CCGG) competed efficiently. To prove that $\mathrm{E} 2 \mathrm{~F}$, or a related transcription factor, binds to the MYC promoter, similar competition experiments were performed using the labeled fragment f-E2F originating from the E1a enhancer of Ad5 carrying two E2F sites (Fig. 2). As shown in Figure 4C, the Mono-Q fraction, screened and identified with $\mathrm{f}-\mathrm{mycP}_{2}$, also had a strong binding activity to $\mathrm{f}-\mathrm{E} 2 \mathrm{~F}$, resulting in the double complex bands $\mathrm{A}^{\prime}$ and $\mathrm{B}^{\prime}$. Bands $\mathrm{A}^{\prime}$ and $\mathrm{B}^{\prime}$ could be competed very efficiently by myc- $9 / 10$ by undigested or HpaII-digested f-Ad5H3-G but not by f-Ad5H3-G cut with FnuDII and not by control DNA sequences or the presence of EDTA. These results prove convincingly that E2F or a transcription factor with a similar recognition sequence binds as a dominant nuclear factor to a $\mathrm{P}_{2}$-specific fragment of the human MYC gene. 


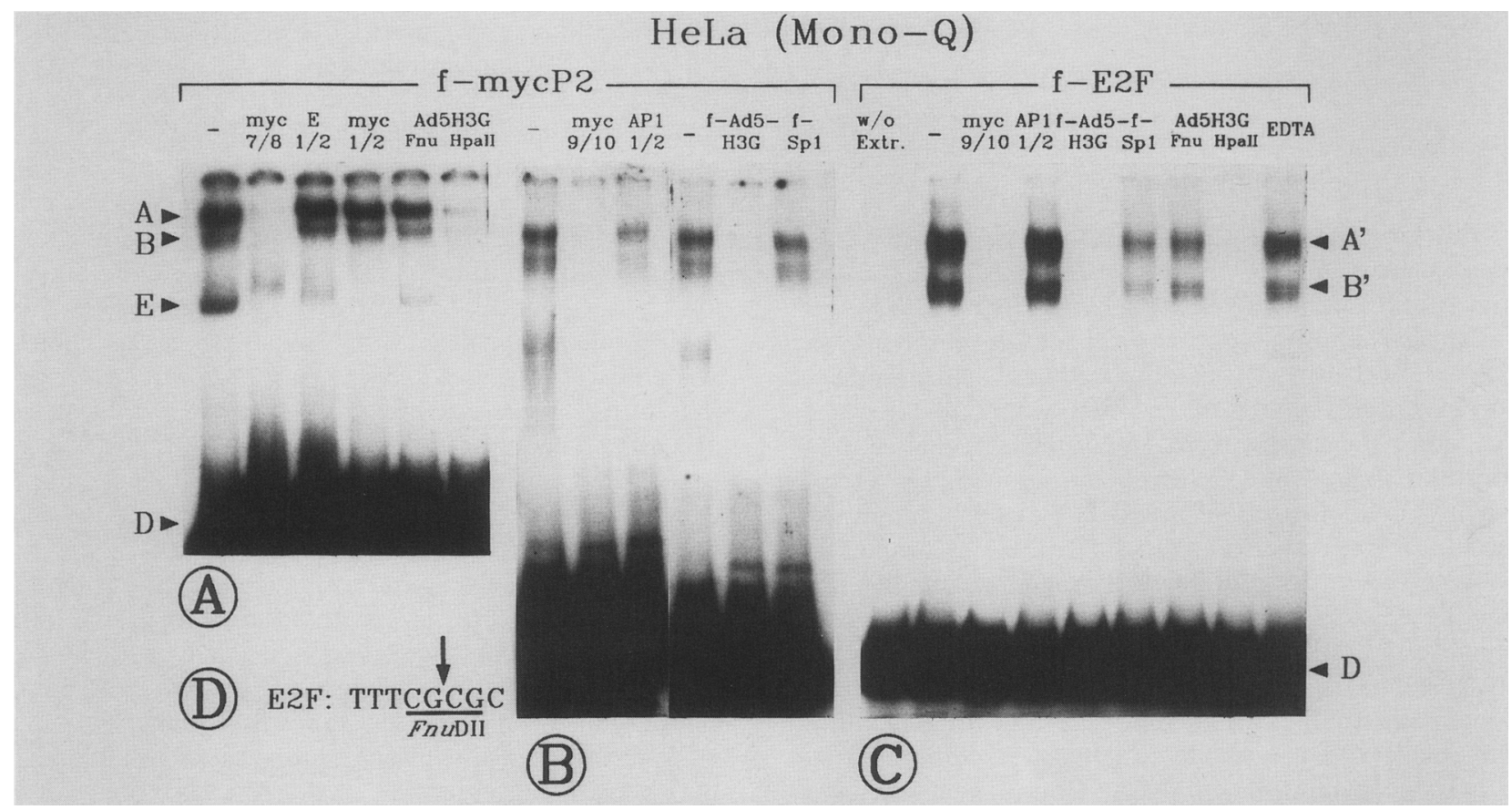

Figure 4. Gel retardation competition analysis of the $M Y C$ promoter $\left(\mathrm{f}-\mathrm{mycP}_{2}\right)$ and $\mathrm{Ad} 5 \mathrm{E}$ la enhancer $(\mathrm{f}-\mathrm{E} 2 \mathrm{~F})$ fragments. End-labeled $\mathrm{f}-\mathrm{mycP}_{2}(A, B, 100 \mathrm{fmole})$ or end-labeled $\mathrm{f}-\mathrm{E} 2 \mathrm{~F}(C, 50 \mathrm{fmole})$ were incubated with a Mono-Q fraction purified from HeLa cells, without $(-)$ or with a 50 -fold molar excess of competitor DNA (for sequence and origin, see Fig. 2). Fragment f-Ad5H3-G was either cut by FnuDII (Fnu) destroying the E2F binding site $(D)$, or by HpaII leaving the E2F site intact. For explanation of complex bands A, B, E, $\mathrm{A}^{\prime}$, and $B^{\prime}$, see text.

The sequence of $\mathrm{G}$ residues protected by DNA methylation (Fig. 3) displays some similarities with the core binding sequence of transcription factor $\mathrm{Spl}$ (see sequence marked by asterisks at bottom of Fig. 1). A recent report of microinjection experiments with $M Y C$ deletion constructs into frog oocytes suggested that Spl should bind to this particular sequence and mediate the observed transcriptional activity (Nishikura 1986). Using in vitro gel retardation assays, we could not obtain any evidence for the binding of Spl to f-mycP ${ }_{2}$. Neither Splspecific fragments (f-Spl, Fig. 2) nor oligonucleotides containing a $\mathrm{Spl}$ consensus sequence (K-1/2 and AP- $1 / 2$, Fig. 2) were able to compete for any of the $\mathrm{f}-\mathrm{mycP}_{2}$-specific complex bands (Fig. 1; Fig. 4B, last lane). The DNA-protein complex formed with labeled f-Spl and crude or partially purified HeLa nuclear extracts could not be competed by the fragment $\mathrm{f}-\mathrm{mycP}_{2}$ or with any $\mathrm{P}_{2}$-specific oligonucleotide (data not shown).

\section{Increasing levels of the MYC binding factor during adenovirus infection}

Because it was shown previously (Kovesdi et al. 1986) that the level of the E2F factor that can bind to the E2 promoter increases in Ad5-infected cells, a similar effect should be observed with the MYC promoter fragment if both factors are identical and have the same properties. Therefore, we prepared nuclear extracts from HeLa cells infected with adenovirus type 12 (Ad12) for increasing time periods and performed gel retardation assays with fragment $\mathrm{f}-\mathrm{mycP}_{2}$. As shown in Figure 5, the complex bands $A$ and $B$ are detected readily in uninfected cells, but a large increase in binding activity is seen at $16 \mathrm{hr}$ after Ad12 infection. Because of the prolonged replication cycle of Ad12 compared with Ad2/Ad5, early viral proteins are synthesized in significant amounts $\sim 12-15$ $\mathrm{hr}$ postinfection. This result confirms again the prior

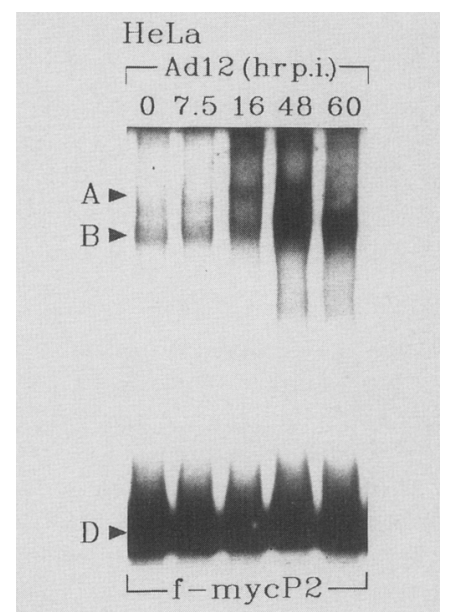

Figure 5. Induction of nuclear factor binding to the $M Y C$ promoter during adenovirus infection. Gel retardation analyses were carried out with 100 fmole end-labeled $\mathrm{f}-\mathrm{mycP}_{2}$ fragment incubated with nuclear extracts that were prepared from HeLa cells after infection with Ad12 (25 pfu/cell). 
conclusion that the factor binding to the $M Y C$ promoter is identical to E2F.

\section{Detection of additional nuclear factors by synthetic oligonucleotides}

In addition, we examined whether oligonucleotides myc-7/8 and myc-9/10 (4 bp longer, Fig. 2), being part of $\mathrm{f}-\mathrm{mycP}_{2}$ and competing efficiently for $\mathrm{E} 2 \mathrm{~F}$, would reveal an identical binding pattern in gel retardation assays as observed with the $\mathrm{P}_{2}$-specific fragment. Surprisingly, upon incubation of labeled myc- $9 / 10$ with crude extracts or a Mono-Q fraction from HeLa cells, in addition to complex bands $\mathrm{A}$ and $\mathrm{B}$, three further complex bands with higher mobilities, denoted F, G, and $H$, could be detected by gel retention analysis (Fig. 6A). Complex $\mathrm{H}$ was observed rather clearly with crude extracts but not with the particular Mono-Q fraction. In contrast, complexes $F$ and $G$ were obtained significantly only with the purified Mono-Q fraction (first lane). Competition experiments with a 50 -fold molar excess of unlabeled homologous or unrelated oligonucleotides demonstrated the specificity of binding (Fig. 6A). Complex bands A and $\mathrm{B}$ disappeared exclusively by competition either with the E1a enhancer fragment $\mathrm{f}-\mathrm{E} 2 \mathrm{~F}$ or with oligonucleotide EF-5/6 (Fig. 2) containing the two E2F binding sites of the Ad5 E2a promoter. Oligonucleotide EF-3/4 (Fig. 2), containing only the intact ATF binding site of the E2a promoter but mutated E2F binding sites, did not compete for complex bands $A$ and $B$. In the reverse experiment (Fig. 6A, last 4 lines) using labeled oligonucleotide EF-5/6, two complex bands, $\mathrm{A}^{\prime}$ and $\mathrm{B}^{\prime}$, were formed, which disappeared by competition with myc-9/10 and EF-5/6 but not with EF-3/4. Thus, the results obtained with the promoter fragment $\mathrm{f}-\mathrm{mycP}_{2}$ were confirmed, indicating again that transcription factor E2F binds specifically to $P_{2}$. The reduced binding of all nuclear factors, especially $F$ and $G$ to myc-9/10 in the presence of $\mathrm{f}-\mathrm{Spl}$, can be explained by the high GC content of this fragment (Fig. 6A).

To investigate a possible cell type specificity of complex bands $F, G$, and $H$ and to study the identity of involved components, we incubated labeled oligonucleotide myc-7/8 with crude nuclear extracts from Burkitt lymphoma cell line BL64 without or in the presence of a 50 -fold and 250-fold molar excess of an unlabeled homologous oligonucleotide of $\mathrm{Al} / \mathrm{B} 1$. This oligonucleotide originated from the left-hand terminal repeat of

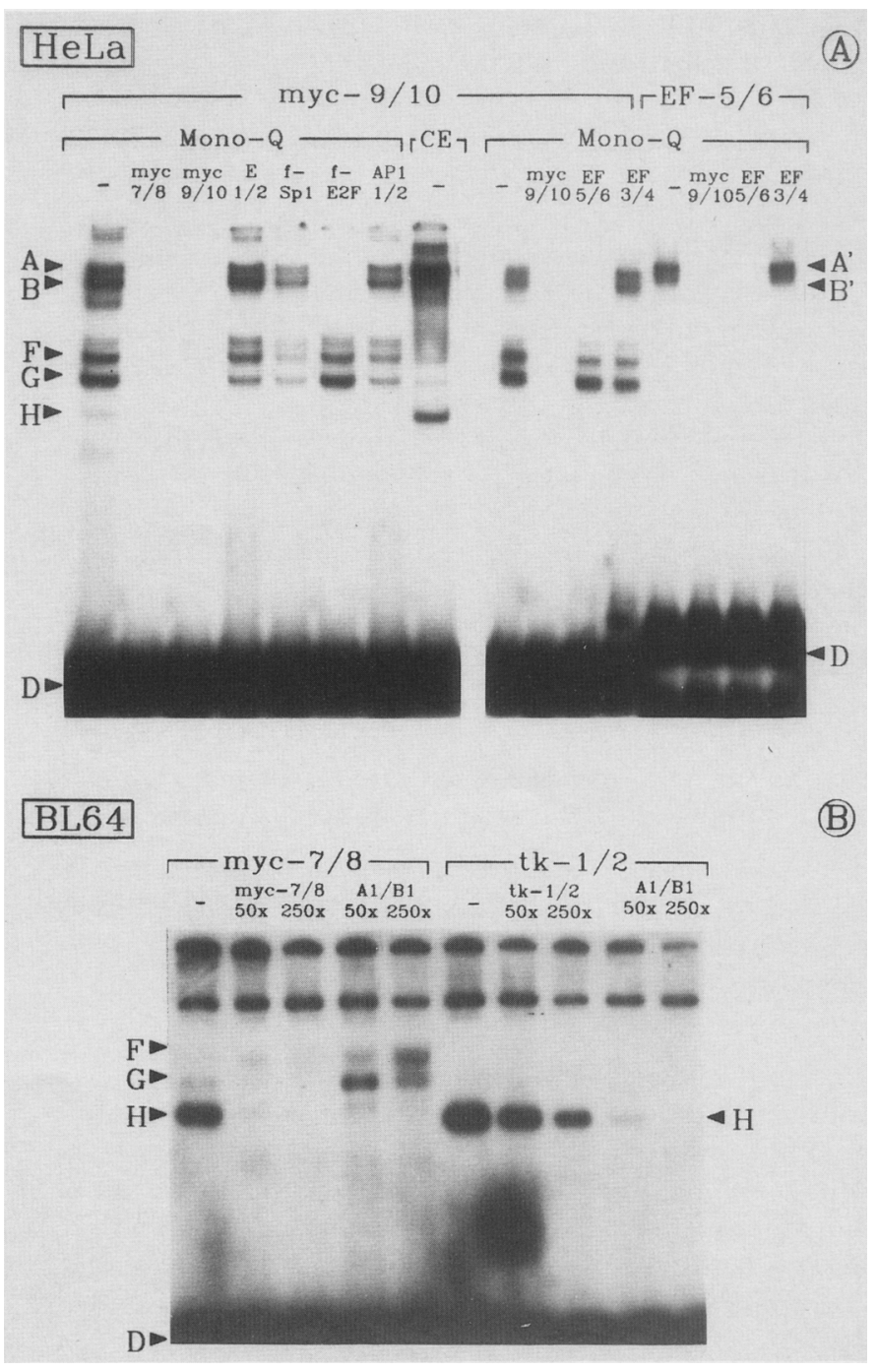

Figure 6. Gel retardation competition analysis of $\mathrm{P}_{2}$-specific oligonucleotides with extracts from $\mathrm{HeLa}(A)$ and BL64 $(B)$ cells. $(A) 10$ fmole of oligonucleotide myc-9/10 (lanes 1-12) or EF-5/6 (lanes 13-16), labeled by the Klenow fragment of DNA polymerase I, was incubated with a Mono-Q fraction purified from HeLa cells or with crude extract (CE). Competition experiments were done by adding a 50 -fold molar excess of the unlabeled competitor DNA indicated above each lane. $(B) 10$ fmole of oligonucleotide myc-7/8 (lanes 1-5) or tk-1/2 (lanes $6-10$ ), labeled as in $A$, were incubated with $5 \mu \mathrm{g}$ of crude nuclear extract from BL64 cells. The molar excess of unlabeled competitor oligonucleotides added to the binding reaction is indicated above each lane. For explanation of complex bands A, B, F, G, H, A', and $B^{\prime}$, see text. (D) Position of unbound DNA. 
adenovirus type $2(\mathrm{Ad} 2)$ containing a binding site of NFI (Fig. 2). Al/B1 was chosen as competitor because a stretch of bases of myc-7/8 (GCCAA) is homologous to one half of the NFI consensus sequence, which is also an incomplete CCAAT box (see also sequence marked by open triangles at bottom of Fig. 1). As shown in Figure 6B (left), complex band $\mathrm{H}$ can be competed efficiently by the homologous, as well as by the NFI-specific oligonucleotide. Interestingly, complex bands F and G, which can be recognized only weakly with the crude extract, suddenly appeared in the presence of an excess of A1/B1. This suggests that binding of $\mathrm{F}$ - and G-specific factors was inhibited by the $\mathrm{H}$-specific component. The control experiment outlined in Figure 6B (right) confirmed the assumption that complex $\mathrm{H}$ belongs to the NFI or CCAAT families of transcription factors, because oligonucleotide tk-1/2 (Fig. 2), containing the canonical CCAAT box of the $t k$ gene of herpes simplex virus type 1 (HSVl), specifically recognized the same factor. In conclusion, a synthetic oligonucleotide representing 38 bp of $\mathrm{P}_{2}$ could form three distinct complexes with overlapping binding sites in addition to the two E2F-specific DNA-protein complexes also observed with the MYC promoter fragment. One of these factors recognized both NFI- and CCAAT-specific sequences and was found to be highly stimulated in the B-cell line BL64 in comparison to HeLa cells.

\section{Functional significance of the E2F binding site for E1a-mediated trans-activation}

We asked whether the E2F-specific binding site, identified in vitro by gel retardation assays and footprint analysis, would also be critical for in vivo promoter activity and trans-activation by E1a. For that purpose, 5'-deletion constructs were generated by Bal31 digestion, which contained portions of the $\mathrm{P}_{2}$ promoter, the complete first noncoding exon, some intron sequences, a synthetic splice acceptor oligonucleotide, and the chloramphenicol acetyltransferase (CAT) gene (Fig. 7). The $M Y C-c a t$ hybrid plasmids were either transfected into
293 and HeLa cells or cotransfected with an Ela-expressing plasmid (pAd5H3-G) into HeLa cells. The enhancement of CAT activity by Ela in HeLa cells and CAT activity in HeLa and 293 cells was determined from cell extracts prepared $40 \mathrm{hr}$ upon transfection. As shown in Figure 7, deletion constructs encompassing position $-2489 \mathrm{bp}(\mathrm{p} 2-2489)$ down to $-66 \mathrm{bp}$ (p2-66), with respect to the transcriptional start site of $\mathrm{P}_{2}$, could be trans-activated significantly by E1 a (about six- to sevenfold) and expressed high levels of CAT activity in 293 cells. Deletion of two additional G residues, which were identified as the outermost contact points by the methylation interference analysis (marked by asterisks in Fig. 7), abrogated trans-activation by Ela completely and diminished CAT activity in 293 cells to $<10 \%$. This activity was reduced further considerably to $\sim 5 \%$ by transfecting plasmid p2-20, which lacks the TATA box.

The analysis of the behavior of promoter deletions in HeLa cells in the absence of Ela proteins confirmed previous observations of a slight negative upstream element (Chung et al. 1986; Hay et al. 1987; Lipp et al. 1987) but also revealed the importance of an intact E2F binding site for full promoter activity of $\mathrm{P}_{2}$ (Fig. 7). The CAT activity was diminished to $<50 \%$ by transfecting plasmid p2-64, which lacks a complete E2F site. The negative element was not detectable in 293 cells, indicating that the efficient activation of $\mathrm{P}_{2}$ can abolish this effect. From these results, we conclude that the E2F binding site contributes to the entire basic activity of the human $M Y C$ promoter and is the critical target for its trans-activation by Ela.

\section{Discussion}

Irrespective of the mechanisms by which nuclear oncogenes might exert their capacity for cell transformation, either directly or possibly through transcriptional control of essential genes involved in differentiation and proliferation, the deregulation of their own expression frequently seems to be one crucial event during multistage tumorigenesis. In the present study we have at-

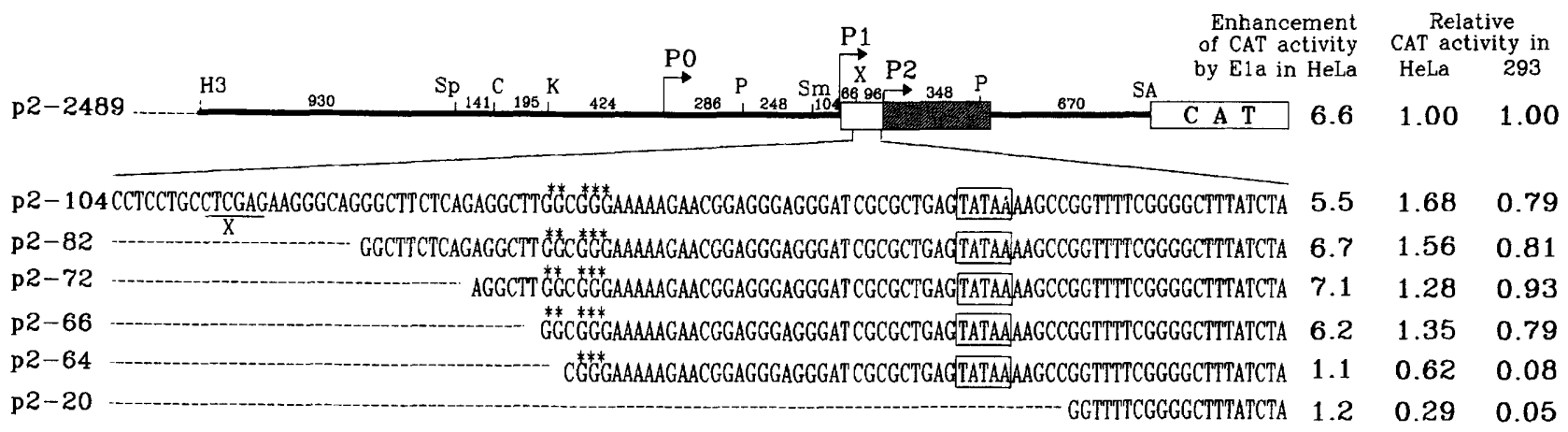

Figure 7. Trans-activation of $5^{\prime}$-deletion constructs of the MYC promoter by Ela and promoter activity in 293 cells. Deletion constructs (15 $\mu \mathrm{g} \mathrm{HeLa}$ or $5 \mu \mathrm{g} 293$ ) were either transfected (HeLa, 293) or cotransfected with $1.5 \mu \mathrm{g}$ pAd5H3-G (HeLa) into the recipient cells. The basic activity and the enhancement of CAT activity by E1A in HeLa cells or the activity in 293 cells was determined from $500 \mu \mathrm{g}$ (HeLa) or $50 \mu \mathrm{g}(293$ ) cellular extract prepared $40 \mathrm{hr}$ upon transfection. The relative CAT activities of $1.0 \mathrm{in} \mathrm{HeLa}$ and $293 \mathrm{cells}$ correspond to $9500 \mathrm{cpm}$ and $140,000 \mathrm{cpm}$, respectively. $\left(^{*}\right) \mathrm{G}$ residues protected in the methylation interference assay (Fig. 3); the TATA motif is boxed. 
tempted to identify nuclear factors, which are able to modulate transcriptional activity of the human $M Y C$ proto-oncogene. We could demonstrate that a nuclear protein binds efficiently and predominantly to an upstream region of the second $M Y C$ promoter $(-58$ to $-67)$. This protein has binding properties identical to those of a transcription factor, recently defined as E2F, which plays an essential role in activating early promoters (E2a) and enhancers (E1a) of adenoviruses by interacting with the virus-encoded Ela proteins (Kovesdi et al. 1987). Most importantly, the $\mathrm{P}_{2}$ promoter of $M Y C$ is the first cellular target described for the E2F factor. $\mathrm{P}_{2}$ also can be trans-activated efficiently by Ela proteins, depending on the presence of an intact E2F binding site. Our results suggest that the activity of $\mathrm{P}_{2}$ can be altered by cellular Ela-like proteins via the E2F transcription factor.

In agreement with experiments reported recently (Kovesdi et al. 1987; Yee et al. 1987), we also obtained two complex bands with a fragment derived from the Ela enhancer and with an oligonucleotide from the E2a promoter of Ad5 carrying both of the two distinct binding sites for E2F. By footprint analysis and by extensive competition experiments, we clearly could establish that the three MYC-specific and the two Ela/E2a-specific protein complexes are recognizing the identical DNA sequence. As summarized in Figure 8, a comparison of the critical DNA sequence within $\mathrm{P}_{2}$ with known binding sites for E2F within the E2a promoter and the Ela enhancer of Ad5 and Ad12 identifies a common element in all sites with the 9-bp consensus sequence $5^{\prime}-(\mathrm{C} / \mathrm{C}) \mathrm{CG}(\mathrm{C} / \mathrm{G})$-GAAAA-3'. Yee et al. (1987) recently proposed the more simple consensus recognition site, $5^{\prime}$-GCGCGAAA-3', for E2F. It is not known yet whether the outermost $A$ residue of the consensus sequence displayed in Figure 8 is necessary for the binding of E2F, because this $\mathrm{A}$ is missing in the second binding site within the E2a promoter. However, the $G$ residue next to the consensus sequence within $\mathrm{P}_{2}$ interfered clearly with E2F binding after methylation (Fig. 3), indicating that this contact point contributed to the stability of the DNA-protein complex.

Surprisingly, the usage of short double-stranded synthetic oligonucleotides in gel retardation assays instead of longer DNA fragments led to the detection of three additional DNA-protein complexes bound to the same

$$
\begin{aligned}
& \text {-79 5'-TTCTCAGAGGCTTGGCGGG AAAAAGAACंGGAG-3'-48 } M Y C \text { (P2) }
\end{aligned}
$$

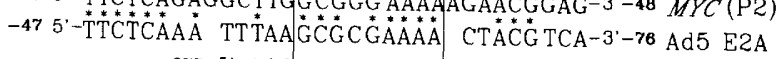

$$
\begin{aligned}
& -277 \text { 5'-ACCGCGCGAAAATTG -3'-291 Ad5 E1a } \\
& -214 \text { 5'-TTCCCGCGAAAATGG-3'-228 Ad5 E1a } \\
& -218 \text { 5'-TAdGCGCGAAAA } \text { CTG }^{-3}-204 \quad \text { Ad12 E1a } \\
& { }_{\mathrm{C}}^{\mathrm{C}}{ }_{\mathrm{G}}^{\mathrm{C}} \text { GAAAA } \\
& \text { consensus }
\end{aligned}
$$

Figure 8. Comparison of the E2F binding sites in Ela-inducible promoters. $\left({ }^{*}\right)$ Sequence homologies between the $\mathrm{P}_{2}$ promoter of the human MYC gene and the E2a promoter of Ad5. The human MYC $\left(\mathrm{P}_{2}\right)$ sequence is identical to the murine promoter sequence, except one nucleotide exchange $(C$ to $G, \bullet)$. The E2F consensus sequence is boxed. region of $\mathrm{P}_{2}$. The binding of one of these nuclear factors could be significantly competed with oligonucleotides carrying a canonical CCAAT box or a NFI consensus binding site (TGGN ${ }_{5}$ GCCAA). This suggests that the sequence $\mathrm{TTC}_{7} \mathrm{GCCAA}$ of the MYC promoter can be recognized by one of the various CCAAT or NFI binding factors described recently (for review, see Jones et al. 1988). We have determined the equilibrium binding constants of purified and cloned NFI from porcine liver to the NFI site of Ad2, to the CCAAT motif of the $t k$ gene of HSVl, and to the MYC promoter sequence, being $2 \times 10^{10}, 1 \times 10^{7}$, and $2 \times 10^{7} \mathrm{M}$, respectively (Meisterernst et al. 1988a,b). These low binding constants argue against an involvement of NFI in the control of MYC. Thus, the functional significance of the particular interactions of nuclear proteins with $M Y C$-specific oligonucleotides remains to be determined experimentally.

However, our results demonstrate directly a functional role of the E2F factor in modulating the activity of the MYC promoter. Based on our finding that the second $M Y C$ promoter can be trans-activated efficiently by Ela proteins of human and mouse adenoviruses (Lipp et al. 1989), we demonstrated by a series of 5 '-deletion constructs that an upstream promoter element, now identified as an E2F binding site, was essential for basic transcription, trans-activation by Ela, and for the high CAT activity in 293 cells (Fig.7). This finding is in agreement with a recent report proposing that trans-activation of early adenovirus promoters is mediated through a transcription factor that binds to the E2 promoter of Ad5 and was therefore denoted E2F (Kovesdi et al. 1987). However, other studies failed to identify another target sequence beside the TATA box necessary for trans-activation of several viral and cellular promoters by E1a (for review, see Berk et al. 1986). This puzzling subject was reexamined very recently, and evidence was presented that only a particular TATA motif, TATAA, is responsible for the trans-activation effect by Ela (Simon et al. 1988). However, the same TATA motifs are present in both $M Y C$ promoters $\left(\mathrm{P}_{1}\right.$ and $\left.\mathrm{P}_{2}\right)$. Under our experimental conditions using a 10-fold smaller amount of a plasmid expressing E1a with respect to the reporter CAT plasmid in the cotransfection assay, we observed a nonsignificant 2- to 3-fold enhancement of CAT activity compared to the substantially higher 6- to 25 -fold transactivation mediated through the E2F elements (Lipp et al. 1989). Recently, it was shown that the human FOS gene is stimulated about sevenfold by Ela, depending on the presence of enhancer upstream sequences (SassoneCorsi and Borelli 1987). However, another study demonstrated that the FOS TATA element is indeed responsive to Ela (Simon et al. 1988). Sassone-Corsi and Borelli (1987) included a MYC-CAT plasmid containing a large promoter fragment $(-2325$ to +36$)$ in their cotransfection analysis. Although these authors observed a stimulation of CAT activity comparable to our results, no further data demonstrating the specificity of this effect were presented.

Two possible mechanisms are discussed as to how Ela can trans-activate: stimulation of the synthesis of a cellular protein or modification of a preexisting factor. Evi- 
dence for the latter possibility was presented recently. These data suggest that activation of E2F occurs as a post-translational event (Reichel et al. 1988). It is of particular importance to see whether transcription of the MYC gene can be regulated due to modification of E2F by cellular factors with similar activities as Ela. The existence of such an Ela-like factor was proposed for F9 undifferentiated teratocarcinoma cells, because an adenovirus Ela mutant can be complemented in those cells (Imperiale et al. 1984). Interestingly, a binding activity of a cellular protein to the E2 promoter of Ad5 was detected in undifferentiated, but not in differentiated, F9 cells (Reichel et al. 1987). It also was shown that MYC mRNA levels decrease when F9 cells are induced to differentiate (Campisi et al. 1984). Recently, on the basis of nuclear run-on analyses, it was proposed that a posttranscriptional control mechanism might be responsible for the observed down-regulation (Dony et al. 1985; Dean et al. 1986). Currently we are testing whether the binding pattern of E2F to the $M Y C$ promoter or its activity is changing during differentiation of $\mathrm{F} 9$ teratocarcinoma cells.

\section{Methods}

Cells

Monolayer cultures of HeLa cells and 293 cells (Graham et al. 1977) were grown in Dulbecco's modified Eagle's medium, and suspension cultures of HeLa cells in Spinner medium supplemented with $5 \%$ fetal calf serum. BL64 cells (Hartl and Lipp 1987) were cultivated in RPMI medium supplemented with $10 \%$ fetal calf serum.

\section{Preparation and purification of nuclear extracts}

Nuclear extracts were prepared by the method of Dignam et al. (1983). Purification of crude extracts by DEAE-cellulose and Mono-Q chromatography has been described recently (Meisterernst et al. 1988a). Fractions were monitored by gel retardation assays using end-labeled synthetic oligonucleotides or isolated DNA fragments.

\section{Gel retardation assays}

Gel retardation assays were performed as described by Schneider et al. (1986). Briefly, a reaction volume of $40 \mu \mathrm{l}$ usually contained 10-100 fmole of double-stranded oligonucleotides or DNA fragment end labeled by Klenow fragment of Escherichia coli DNA polymerase I or T4 polynucleotide kinase, $2 \mu \mathrm{g}$ poly[d(A-T)], and up to $6 \mu \mathrm{g}$ of protein. Extracts were preincubated with the carrier DNA for $10 \mathrm{~min}$ on ice, and the binding reaction was carried out at room temperature for $5 \mathrm{~min}$. DNA-protein complexes were separated from free DNA, either on $5 \%$ polyacrylamide gels if labeled fragments were tested or on $11 \%$ polyacrylamide gels for oligonucleotides.

\section{Methylation interference footprint analysis}

The 188-bp NotI/NaeI fragment of MYC (-141 to +47 with respect to $\mathrm{P}_{2}$ ) was isolated, methylated partially with dimethylsulfoxide (DMSO), as described by Maxam and Gilbert (1977), and incubated with crude nuclear extracts of 293 and BL64 cells as described above. After separation of DNA-protein complexes on a $5 \%$ polyacrylamide gel, complex bands and free
DNA were identified by short exposure to an X-ray film, cut out from the gel, melted into a $0.8 \%$ agarose gel, and transferred electrophoretically to NA45 paper (Schleicher \& Schüell). Then the DNA was eluted and purified as described by the manufacturer, treated with piperidine, and analyzed on a $5 \%$ urea sequencing gel.

\section{Plasmids}

For cloning of the $5^{\prime}$-deletion constructs of the $M Y C$ promoter, a special CAT vector, pUC-CAT-SA, was constructed: A 25-bp synthetic oligonucleotide

\section{ctagaGCTCCAGCAGCCTCCCGCGA tCGAGGTCGTCGGAGGGCGCTctag}

containing the original splice acceptor site of exon two and a $5^{\prime}$ $X b a I$ and a $3^{\prime}$ BglII site, was inserted into the $X b a I$ and $B g I I I$ site of vector pUC-CAT2 (Lipp et al. 1987). To construct p2-2489, the 3507-bp HindIII-XbaI fragment cloned from the nontranslocated MYC allele of cell line BL64 (Hartl and Lipp 1987) was inserted into vector pUC-CAT-SA, digested with HindIII and $X b a I$. The deletion constructs p2-104 to p2-20 were obtained by opening a pUC12-derived plasmid carrying the 3507-bp HindIII-Xbal fragment with SmaI, followed by Bal31 digestion, fill-in reaction, and ligation after adding HindIII linkers. This mixture was digested with HindIII and $\mathrm{XbaI}$; fragments of different size classes were isolated from an agarose gel and ligated into pUC-CAT-SA. Deletion constructs within $\mathrm{P}_{2}$ were identified by colony hybridization with oligonucleotide myc- $7 / 8$ and increasing stringency during the washing procedure.

\section{DNA transfection and CAT assays}

Transfection with a total amount of $20 \mu \mathrm{g}$ superhelical plasmid DNA (pUC12 was used as carrier) per $10^{6}$ cells in 9-cm tissue culture dishes was performed by the calcium phosphate coprecipitation technique, and determination of CAT activity was carried out essentially as described previously (Lipp et al. 1987). The amounts of the monoacetylated forms of chloramphenicol were measured and computed with a thin-layer scanner (TCL-510, Berthold, Bad Wildungen).

\section{Acknowledgments}

We thank T. Dörper for providing us with the construct pAd5H3-G, and M. Meisterernst for the gift of nuclear extracts from HeLa cells. We express our gratitude to I. Kruczek for providing nuclear extracts from Ad12-infected HeLa cells, for helpful suggestions, and discussions. We thank $H$. Ibelgaufts for critically reading the manuscript. We are grateful to Renate Schilling for her skillful technical assistance. The work was supported by the Deutsche Forschungsgemeinschaft through the Forschergruppe 'Virus-Zell-Wechsel-wirkung' (Fa 138/3-1) and the SFB 304 'Organisation des Eukaryontengenoms.'

\section{References}

Bently, D.L. and M. Groudine. 1986. A block to elongation is largely responsible for decreased transcription of c-myc in differentiated HL60 cells. Nature 321: 702-706.

Berk, A.J. 1986. Adenovirus promoters and E1A transactivation. Annu. Rev. Genet. 20: 45-79.

Campisi, J., H.E. Gray, A.B. Pardee, M. Dean, and G.E. Sonenshein. 1984. Cell-cycle control of c-myc but c-ras expression is lost following chemical transformation. Cell 36: 241247.

Chung, J., E. Sinn, R.R. Reed, and P. Leder. 1986. Trans-acting elements modulate expression of the human c-myc gene in 
Burkitt lymphoma cells. Proc. Natl. Acad. Sci. 83: 79187922.

Dean, M., R.A. Levine, and J. Campisi. 1986. c-myc regulation during retinoic acid-induced differentiation of F9 cells is posttranscriptional and associated with growth arrest. Mol. Cell. Biol. 6: 518-524.

Dignam, J.D., R.M. Lebovitz, and R.G. Roeder. 1983. Accurate transcription initiation by RNA polymerase II in a soluble extract from isolated mammalian nuclei. Nucleic Acids Res. 11: $1475-1489$.

Dony, C., M. Kessel, and P. Gruss. 1985. Post-transcriptional control of myc and $\mathrm{p} 53$ expression during differentiation of the embryonal carcinoma cell line F9. Nature 317: 636-639.

Eick, D. and G.W. Bornkamm. 1986. Transcriptional arrest within the first exon is a fast control mechanism in c-myc gene expression. Nucleic Acids Res. 14: 8331-8346.

Graham, F.L., J. Smiley, W.C. Russell, and R. Nairn. 1977. Characteristics of a human cell line transformed by DNA from human adenovinus type 5. J. Gen. Virol. 36: 59-74.

Hartl, P. and M. Lipp. 1987. Generation of a variant $t(2 ; 8)$ translocation of Burkitt's lymphoma by site-specific recombination via the kappa-light chain joining signals. Mol. Cell. Biol. 7: 2037-2045.

Hay, N., J.M. Bishop, and D. Levens. 1987. Regulatory elements that modulate expression of human c-myc. Genes Dev. 1: $659-671$.

Imperiale, M.J., H.-T. Kao, L.T. Feldman, J.R. Nevins, and S. Strickland. 1984. Common control of the heat shock gene and early adenovirus genes: Evidence for a cellular Ela-like protein. Mol. Cell. Biol. 4: 867-874.

Jones, N., P.W.J. Rigby, and E.B. Ziff. 1988. Trans-acting protein factors and the regulation of eukaryotic transcription: Lessons from studies on DNA tumor viruses. Genes Dev. 2: $267-281$.

Klein, G. and E. Klein. 1985. Evolution of tumours and the impact of molecular oncology. Nature 315: 190-195.

Kovesdi, I., R. Reichel, and J.R. Nevins. 1986. Identification of a cellular transcription factor involved in Ela trans-activation. Cell 45: 219-228.

. 1987. Role of an adenovirus E2 promoter binding factor in E1A-mediated coordinate gene control. Proc. Natl. Acad. Sci. 84: 2180-2184.

Lipp, M., R. Schilling, and G. Bernhardt. 1989. Trans-activation of human MYC: The second promoter is target for the stimulation by adenovirus Ela proteins. Oncogene 4: (in press).

Lipp, M., R. Schilling, S. Wiest, G. Laux, and G.W. Bornkamm. 1987. Target sequences for cis-acting regulation within the dual promoter of the human c-myc gene. Mol. Cell. Biol. 7: $1393-1400$.

Maxam, A.M. and W. Gilbert. 1977. A new method for sequencing DNA. Proc. Natl. Acad. Sci. 74: 560-564.

Meisterernst, M., I. Gander, L. Rogge, and E.-L. Winnacker. 1988a. A quantitative analysis of nuclear factor I/DNA interactions. Nucleic Acids Res. 16: 4419-4435.

Meisterernst, M., L. Rogge, C. Donath, I. Gander, F. Lottspeich, R. Mertz, T. Dobner, R. Föckler, G. Stelzer, and E.-L. Winnacker. 1988b. Isolation and characterization of the porcine nuclear factor I (NFI) gene. FEBS Lett. 236: 27-32.

Nishikura, K. 1986. Sequences involved in accurate and efficient transcription of human c-myc genes microinjected into frog oocytes. Mol. Cell. Biol. 6: 4093-4098.

Pfeifer, K., T. Prezant, and L. Guarente. 1987. Yeast Hapl activator binds to two upstream activation sites of different sequence. Cell 49: 19-27.

Piechaczyk, M., J.-M. Blanchard, and P. Jeanteur. 1987. c-myc regulation still holds its secret. Trends Genet. 3: 47-51.
Reichel, R., I. Kovesdi, and J.R. Nevins. 1987. Developmental control of a promoter-specific factor that is also regulated by the ElA gene product. Cell 48: 501-506.

1988. Activation of a preexisting cellular factor as a basis for adenovirus E1A-mediated transcription control. Proc. Natl. Acad. Sci. 85: 387-390.

Sassone-Corsi, P. and E. Borelli. 1987. Promoter trans-activation of protooncogenes c-fos and c-myc, but not c-Ha-ras, by products of adenovirus early region 1A. Proc. Natl. Acad. Sci. 84: 6430-6433.

Schneider, R., I. Gander, U. Mueller, R. Mertz, and E.L. Winnacker. 1986. A sensitive and rapid gel retention assay for nuclear factor I and other DNA-binding proteins in crude nuclear extracts. Nucleic Acids Res. 14: 1303-1317.

Simon, M.C., T.M. Fisch, B.J. Benecke, J.R. Nevins, and N. Heintz. 1988. Definition of multiple, functionally distinct TATA elements, one of which is a target in the hsp70 promoter for ElA regulation. Cell 52: 723-729.

Yang, J.-Q., E.F. Remmers, and K.B. Marcu. 1986. The first exon of the c-myc proto-oncogene contains a novel positive control element. EMBO I. 5: 3553-3562.

Yee, A.S., R. Reichel, I. Kovesdi, and J.R. Nevins. 1987. Promoter interaction of the E1A-inducible factor E2F and its potential role in the formation of a multi-component complex. EMBO /. 6: 2061-2068. 


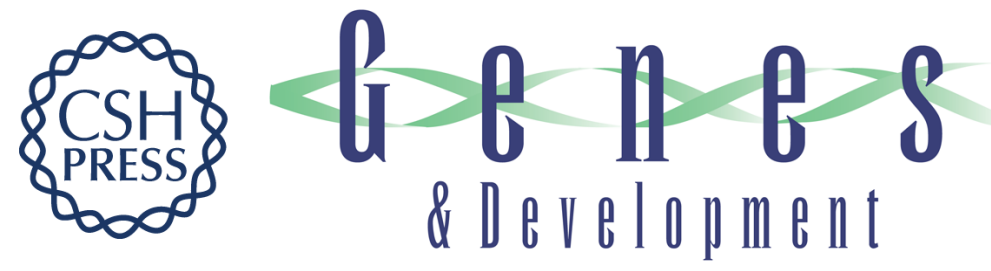

\section{Nuclear factor E2F mediates basic transcription and trans-activation by E1a of the human MYC promoter.}

K Thalmeier, H Synovzik, R Mertz, et al.

Genes Dev. 1989, 3:

Access the most recent version at doi:10.1101/gad.3.4.527

References This article cites 30 articles, 12 of which can be accessed free at: http://genesdev.cshlp.org/content/3/4/527.full.html\#ref-list-1

License

Email Alerting

Service

Receive free email alerts when new articles cite this article - sign up in the box at the top right corner of the article or click here.

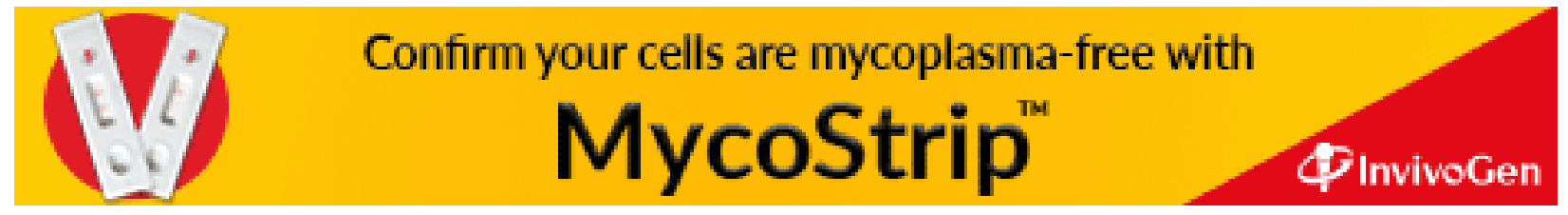

